\title{
Does Knowledge Contribute to the Acceptance of Demand Response?
}

\author{
Salla Annala*, Satu Viljainen, Jussi Tuunanen, Samuli Honkapuro \\ LUT Energy, \\ Lappeenranta University of Technology, Finland \\ e-mail: $\underline{\text { salla.annala@lut.fi }}$
}
Cite as: Annala, S., Viljainen, S., Tuunanen, J., Honkapuro, S., Does Knowledge Contribute to the Acceptance of Demand Response?, J. sustain. dev. energy water environ. syst., 2(1), pp 51-60, 2014, DOI: http://dx.doi.org/10.13044/j.sdewes.2014.02.0005

\begin{abstract}
More flexible demand side would benefit the electricity markets, networks and sustainable power generation in many ways. The success of demand response programs, however, relies on consumer acceptance. This paper reviews previous studies about acceptability of different kinds of residential demand response programs. Furthermore, it discusses whether consumers who are more aware of the principles and benefits of demand response have more positive attitudes towards demand response programs. The results of the literature review and two survey studies suggest that price and security of supply are currently bigger motives to change consumption behaviour than environmental issues and that the savings expected to trigger any action (and to lead to lasting change in behaviour) may be relatively high. Therefore, the framing of demand response programs goals may affect the acceptance. Additionally, consumers seem to prefer simple price structures that remain constant for a long time to more dynamic options.
\end{abstract}

\section{KEYWORDS}

Demand response, Load control, Time-varying prices, Consumer behaviour, Acceptability, Electricity

\section{INTRODUCTION}

Demand response which is typically defined as changes in consumers' electricity use patterns in response to changes in the electricity price or to incentive payments that aim to lower consumption during high wholesale market prices or when system reliability is at risk [1] is often seen as a solution to various issues in the electricity markets and power systems.

Demand response has the potential to increase the overall efficiency of the power system. Generation and network infrastructure have to be planned according to the maximum power demand. Shifting consumption away from peak hours could, therefore, help reduce the need for network and generation investments [2, 3]. It could lower the wholesale market prices if the use of the power plants with the highest marginal costs can be avoided during periods when demand would otherwise be high [2]. Demand response could also help mitigate market power and prevent prices that are significantly higher than production costs [2]. Participating customers could benefit from lower electricity bills if they adjust their electricity consumption in response to the time-varying rates or incentive payments [2,3].

The need to increase the sustainability of the power system has increased the emphasis on demand response. Shifting consumption from peak to off-peak hours may

*Corresponding author 
reduce the environmental impacts of electricity use because the peak demand is often supplied with fossil fuels [4]. Further, demand response can help match demand with intermittent renewable generation (e.g. wind, solar). In some cases, the implementation of time-varying prices has reduced not only the on-peak consumption but also the overall consumption [5].

So far, majority of demand response studies have focused on the technical potential. Because the success of demand response programs relies on consumer acceptance, increasing attention has to be paid to how consumers see the different pricing structures and direct control of their appliances. This paper studies what would motivate residential customers to take part in different demand response programs and what kind of activities they would be willing to shift. Furthermore the paper discusses whether consumers who are more aware of the concept of demand response have more positive attitudes towards demand response programs.

The paper is organized as follows. The literature review provides examples of residential demand response programs and reviews consumer perceptions and experiences about different pricing structures and shifting of electricity consumption. The following section provides data from two questionnaire studies (one aimed to the general public and the other to demand response specialists) about the acceptability of demand response. The last section concludes the paper.

\section{CONSUMER PERCEPTIONS ABOUT DEMAND RESPONSE PROGRAMS}

Demand response programs can be divided to incentive- and time-based (also referred to as price-based) programs. In incentive-based demand response programs (for example direct load control and emergency demand respond) consumers are paid for reducing their electricity use when the program organizer requests it (typically because of reliability risks or high market prices) $[1,2]$. Time or price-based programs, such as time-of-use (TOU) pricing, real-time pricing (RTP) and critical peak pricing (CPP), rely on consumers to voluntarily modify their consumption based on time-varying electricity rates $[1,2]$. Both incentive- and time-based programs for residential customers often involve remote control of consumers' electric appliances (typically electric space and water heaters or air conditioners). In incentive-based programs, consumers may be given a fixed reduction in their electricity bill in exchange for allowing remote control of their appliances when the system reliability is jeopardized (see [6, 7]).

Time of use (TOU) pricing applies higher prices for consumption during on-peak than on off-peak hours (sometimes more price levels, e.g. mid-peak). The time zones are constant and the prices applied during them are fixed for a long time. TOU tariffs have been thought to benefits larger user with electric space or water heating and in Europe, they have been recommended to customers who use a certain amount of electricity at night [8]. For example in Finland, about $85 \%$ of households with electric heating are on TOU tariffs whereas the overall penetration of TOU is $17 \%$ [8]. In Italy, however, regulated electricity tariffs that are used by majority of residential customers have been two-period TOU tariffs since July 2010 [8]. TOU tariffs and direct control of electric heating have been used for decades in many countries. The opening of electricity markets, increased amount of renewables, and the development of technology (e.g. smart meters) have further highlighted the benefits of demand response.

In the 2000's, also more dynamic tariff structures, such as critical peak pricing (CPP), have been tested on residential customers $[9,10]$. In CPP, a predefined high rate is applied on limited number of days or hours [1]. CPP may apply basic TOU rates on most days but on event days (e.g. when wholesale prices are very high or the reliability is jeopardized) the normal peak price is replaced with a considerably higher CPP event price [2]. The 
California Statewide Pricing Pilot (SPP, July 2003 to December 2004), for example, tested two variations of CPP [9]. In CPP-F, the timing of the critical peak period (and thus the time of high prices) was fixed and customers were notified day-ahead. In CPP-V, the length of the peak period varied and customers were notified on the same day. The CPP-V customers, however, could choose to have enabling technology installed free of charge. The customers with enabling technologies reduced their electricity consumption during critical prices considerably more than the customers who did not have such technologies installed. Enabling technologies have been noticed to play a key role also in other dynamic pricing experiments [11]. Alternatively to applying high prices for consumption during peak hours, critical peak rebate (CPR) (or peak time rebate) programs compensate consumers who use less than a defined baseline quantity during events.

In real-time pricing (RTP), prices typically fluctuate hourly (or more often) reflecting the wholesale price and customers are notified day-ahead or hour-ahead [1,2]. RTP is often considered critical component of restructured electricity market [12]. Typically it has been applied only to large customers. Allcott [13] evaluates the first hourly RTP program for residential customers. Based on consumer reactions to the Energy-Smart Pricing Plan that has operated in Chicago since 2003, Allcott [13] states that "residential RTP should perhaps be thought of as a peak energy conservation program, instead of a mechanism to shift consumption from peak to off-peak."

\section{Consumer perceptions about time-varying prices}

Dütsche and Paetz [14] analyzed what kind of pricing schemes consumers would prefer. Their study showed preference for a pricing scheme with fixed rates following a fixed timetable over more dynamic options (scheme with three pre-defined price levels changing on an hourly basis, and a scheme with prices varying freely within a given range which was evaluated lowest). Furthermore, a low price spread (15-25€ct/kWh) was preferred to an option with a higher spread (10-35 €ct/kWh) and an automated response (smart appliances) to manual control of appliances. Out of the three attributes (dynamics, price spread, manual/automated response), the dynamics had the highest influence on the evaluation of the program.

Ontario Energy Board Smart Price Pilot (OSPP) tested consumer reactions to time-sensitive electricity prices (TOU, TOU with CPP and TOU with a CPR) and the understandability and acceptability of the pricing structures [5]. The TOU tariff had three price levels (off-peak, mid-peak, on-peak). In TOU with CPP and CPR, critical events lasting 3-4 hours during on-peak period were told to be invoked up to nine times during the pilot. Based on a survey targeted to the participants of all three groups, most participants preferred the TOU-only option to TOU with CPP/CPR. The TOU-only option was also liked better than the tariff the customer were on before the pilot, a two tier pricing in which a lower price was applied for the first $600 \mathrm{kWh}$ per month in summer $(1000 \mathrm{kWh}$ per month in winter) and higher price for consumption exceeding that. The TOU-only participants were less likely to be interested in CPP and CPR than the pilot participants who had been on these tariffs. However, the TOU-only was the most preferred option also among CPP and CPR participants. The pilot participants thought that being aware of how to reduce bill was the most important benefit of TOU pricing. A little over half found the benefits to environment important.

Also other TOU pricing pilots have been conducted in Ontario. According to Hydro One [15], the most frequently used reasons to refuse to participate in their pilot were "I do not like being told by Hydro One when and how to use electricity", "I am already conserving as much as I can", "I will deal with the new rates when necessary", and "I am a stay-at-home mother/retired, and these rates will increase my expenses". Ericson [16] on the other hand 
noted that households with energy management systems and wood-burning furnaces are more likely to join CPP programs than other households.

\section{Changes in consumption behaviour}

Typically the household consumption that is shifted (or considered shiftable) in response to time-varying prices focuses on the use of dishwashers, washing machines and tumble dryers [5, 13, 17-19]. There are still limitations for shifting these activities, as Paetz et al. [17] note that in TOU tariffs the low-price zones should not start too late so that noise from the machines would not cause conflicts with household members and neighbours. In OSPP, some families with small children found it difficult to curtail the laundry activity during on-peak and mid-peak periods [5]. Further, in [20] TOU pilot participants were most likely to refer to concerns about convenience $(53 \%$ of respondents) and safety (53\%) as reasons for not switching usage to night time. Other typical changes made in reaction to time-varying prices are typically related to the use of air conditioners (increasing set-point, turning down, using fans instead of air conditioners) $[5,13,18]$.

Consumption related to cooking and entertainment is typically considered unshiftable. In a questionnaire study aimed participants of a TOU pilot in Sacramento, California, $28 \%$ of respondents reported changing their cooking habits [18]. Changing meal times did, however, cause disagreements in some families. Furthermore, households with elderly or sick residents found increasing temperature difficult. Therefore, [18] pointed out that "conservation and time-of-use shifting may be stressful to individuals and families, whether or not efforts are needed or effective from a power system point-of-view." In [18] some TOU pilot participants also stated they had reduced the use of tumble dryer and installed more efficient lights and majority of pool owners had changed the way the use the pool pump.

One of the outcomes of the OSPP was the participants' better ability to shift load in the summer than in the winter [5]. The main changes were made in on-peak and critical peak period consumption, mid-peak had less influence. A TOU pricing pilot conducted in New Zealand, on the other hand, noted a significant peak-period conservation in winter but no statistically significant effect on peak consumption when averaged over the whole year [21]. The seasonal variation in reactions to TOU prices may be explained by the difference in heating methods. In New Zealand, residential electricity consumption peaks in winter because of wide use of electric heating [21] whereas majority of the OSPP participants used gas for space heating and gas or oil for water heating but the penetration of air conditioners was high [5].

\section{Possible barriers}

Applying time-varying rates requires smart electricity meters. Many studies [17, 22, 23] have highlighted that consumers have concerns related to data privacy of smart meters. If smart meters are not installed to all customers, the acquisition cost may act as a barrier. For example in [17] the expected payback time for acquiring smart meter was one year.

Moreover, consumers lack knowledge about the functioning of electricity markets and about their own electricity consumption patterns [2]. Modifying electricity consumption based on price signals is likely to require cognitive effort and persistence. According to [2] consumers may grow tired of making frequent and active consumption decisions because electricity has traditionally been considered a routine and passive purchase. Especially if the savings of modifying behaviour are seen as too small, the consumers may retain to their old consumption habits. For example, in an Irish TOU 
study [20] the most important reason for not reducing peak usage was giving up after not being able to link behavioural changes to bill reduction. According to [20] this reaction may have been due to exaggerated saving expectations.

\section{SURVEY RESULTS}

This section presents results of two separate questionnaire studies made in Finland. The expert survey was carried out in a workshop of the Smart Grids and Energy Markets (SGEM) research program. The workshop was held in September 2012 and most of its 106 participants, representing both industry and universities, were specialists in electricity networks and markets. Thirty-two workshop participants returned a filled questionnaire that screened specialists' own willingness to take part in demand response programs.

The expert questionnaire was developed partly based on the results of a previous study about the acceptability of remote control of consumers' electric appliances. The study was aimed at the general public and it was conducted online in December 2011 and answered by 2103 persons (detailed results of this survey are presented in [24]). The respondents of the online study are referred to as non-expert respondents whereas the respondents who participated in the workshop in 2012 are referred to as expert respondents.

The two surveys enable us to compare whether people, who are more aware than the general public about the concept of demand response and its benefits to the electricity system, are more willing to participate in demand response programs and whether their motives to take part are the same as the motives of the general public.

Table 1 shows what the non-expert respondents ticked as the reason for which they would allow remote control of their electric appliances (the preface of the survey highlighted the control of electric space and water heating). Furthermore, the respondents were asked about what would worry them, if their appliances would be remotely controlled. These results are shown in Table 2.

Table 1. Reasons for allowing remote control of electric appliances, non-expert respondents [24]

\begin{tabular}{lc}
\hline & Proportion of respondents \\
\hline Savings in electricity costs & $74 \%$ \\
Possibility to remote control yourself & $32 \%$ \\
Reduced emissions & $29 \%$ \\
For no reason & $14 \%$ \\
\hline
\end{tabular}

Table 2. Worries related to remote control of electric appliances, non-expert respondents [24]

\begin{tabular}{lc}
\hline & Proportion of respondents \\
\hline Functioning of control system in agreed manner & $45 \%$ \\
Adequacy of hot water & $34 \%$ \\
Drop in room temperature & $30 \%$ \\
Freezing of water pipes & $15 \%$ \\
\hline
\end{tabular}

Outside the given list, the respondents' main concerns were the desire to retain full control of own appliances and worries about the system's flexibility in case there would be changes in consumers' own needs. Data security of the system was also questioned. However, based on [24], the most important barrier for residential demand response may 
well be the high savings expectations. About half of respondents whose annual electricity consumption was less than $2000 \mathrm{kWh}$ expected to save more than $50 € / \mathrm{a}$ to allow direct load control. For residential electricity customers who consume $2000 \mathrm{kWh} / \mathrm{a}$ the average annual electricity cost with prices in force at the time of questionnaire was $355 €$. For those whose annual consumption was bigger, also the savings expectations were considerably higher.

The expert respondents were first asked about whether they would take part in a demand response program if they would benefit financially. At this point, it was not defined whether the program would involve mere price signals or also direct load control. Thirty respondents stated they would and only one that he/she would not. The experts were also asked how big annual saving they would expect. The median saving expectation was $100 € / \mathrm{a}$, minimum 1 $€ / \mathrm{a}$, and maximum $500 € / \mathrm{a}$. Furthermore, three respondents expressed their saving expectation as percentage of electricity costs. All these respondents expected a saving of $10 \%$.

Because some of the pricing schemes designed to induce demand response, especially RTP, imply that consumer cannot know the impact on his/her electricity costs when signing for the program, the experts were asked about whether they would take part in a demand response program if they could not calculate the outcome. This question divided the respondents as exactly half said they would and half that they would not. One of those who ticked the yes box had, however, added that "if the outcome for me is positive, not negative".

The literature review showed that residential consumers are typically not willing or able to significantly change their daily routines based on electricity prices. From the experts, 18 stated they would accept that demand response sometimes affects their everyday life. Furthermore, because a major concern expressed by the non-expert respondents was whether the control system always functions in the agreed manner, the experts were asked whether they would be willing to take risks related to malfunction of control of electric heating. The results are shown in Table 3.

Table 3. Number of expert respondents that would be willing to take the following risks

\begin{tabular}{lc}
\hline & Number of respondents \\
\hline Sometimes left without hot water & 7 \\
Electricity supply is sometimes accidentally cut off entirely & 2 \\
Room temperature occasionally drops more than agreed & 25 \\
\hline
\end{tabular}

The way the purpose of a demand response program is framed may affect the acceptability of the program even if its effect on the individual would be the same. In the residential survey, reliability-related reasons were not listed when the respondent were asked about their motives to allow remote control. This is because the reliability of electricity distribution is relatively good in Finland and majority of outages have been related to weather conditions instead of lack of transmission and generation capacity. However, for example in the US, many demand response programs focus on the reliability aspects and appeal the consumers to "help keep the lights on". To test the effects of framing the problem, the expert respondents were asked whether they would accept remote control of their appliances if it was needed to maintain a reliable power system and if it was needed to ensure sustainable power generation. In both cases, the respondents could also state whether they would expect compensation. These results are shown in Table 4 (as number of responses). 
Table 4. Acceptance of remote control of electric appliances and expected compensation, expert respondents

\begin{tabular}{lccc}
\hline Framing & No & $\begin{array}{c}\text { Yes, without monetary } \\
\text { compensation }\end{array}$ & $\begin{array}{c}\text { Yes, for monetary compensation } \\
\text { (minimum, maximum, median) }\end{array}$ \\
\hline $\begin{array}{l}\text { Reliability of power } \\
\text { system }\end{array}$ & 1 & 9 & $\begin{array}{c}21 \\
(50 € / \mathrm{a}, 250 € / \mathrm{a}, 100 € / \mathrm{a})\end{array}$ \\
\hline $\begin{array}{l}\text { Sustainability of } \\
\text { electricity generation }\end{array}$ & 6 & 9 & $\begin{array}{c}15 \\
(50 € / \mathrm{a}, 200 € / \mathrm{a}, 100 € / \mathrm{a})\end{array}$ \\
\hline
\end{tabular}

Over third of the respondents (12) gave different conditions for allowing remote control depending on how the control was framed. About the same amount (11) would allow the control in both cases for compensation (and named the same compensation in both cases or named no sum in either case). Six respondents would allow the control without any monetary compensation regardless of the framing. One would not accept the control in either case even for compensation.

The costs of smart meters and demand response enabling technologies are often listed among the main barriers for demand response. Furthermore, there is lack of guidelines about who should bear the technology costs which may be high compared to the possible savings especially for residential customers.

Twenty of the expert respondents would be willing to invest in demand response enabling technologies. Of those 13 that named the sum they would invest, the median was $150 €$ and the maximum $1000 €$. If we compare the sum these 13 would be willing to invest in enabling technologies to what they stated as the annual expected benefit for participating in a demand response program, the expected payback times vary between 0.25 and 10 years. The median was two years.

\section{DISCUSSION AND CONLUSIONS}

Achieving more flexible demand would benefit the electricity markets, networks and sustainable power generation. However, recruiting especially residential customers for demand response programs is likely to be challenging. So far, residential electricity consumers have been rather passive in using their opportunity to switch supplier even if it would lead to lower electricity costs [25]. Sometimes changing the default tariffs to dynamic rates is discussed as an option to overcome the consumer inertia. An opt-out approach could, however, have adverse consequences and lead to backlash towards the smart grid plans [26]. Simpler time-varying tariffs, such as TOU, have gotten positive feedback from pilot and survey participants as adapting consumption based on constant time zones is likely to be easier than on more dynamic tariffs. In the OSPP [5], also customers who had experience of CPP and CPR liked traditional TOU better. Consumers also have positive attitudes towards technologies that help to shift consumption.

The opportunity to save money is the major reason for changing electricity consumption patterns and to allowing remote control of electric appliances. However, there is evidence that households will return to their old consumption habits if they cannot see the impact of their behavioural changes in their electricity bill or if the savings are not considered worth the bother. Furthermore, much of the household consumption (e.g. cooking) is considered unshiftable and the ability/willingness to shift consumption that causes noise is limited in for example apartment houses and in households with children. Households with air conditioners or electric heating (especially if they have also another heating system) may have better chances of tuning their consumption. 
To study whether knowledge about the concept of demand response increases its acceptance, a questionnaire study was conducted at a workshop of the Smart Grids and Energy Markets research program. The participants of the workshop presented electricity network companies, electricity suppliers, network and control system manufacturers, ICT providers, and universities. Thus, the interests of these parties are likely to be reflected in the responses. Furthermore, the small sample in the expert survey limits the strength of the conclusions.

The money savings seemed to be the biggest demand response motivator also for the expert respondents as majority expected to be compensated for allowing remote control of their appliances even if the control would be related to maintaining reliability or to promote sustainable power generation. Furthermore, third of the expert respondents gave different conditions for allowing remote control of their appliances depending on the motive of the control. This supports the presumption that the framing of the demand response program is likely to affect its acceptability. Also Gyamfi and Krumdieck [27] noticed that price and supply security affect motivation to change consumption behaviour more than environmental factors. Because environmental aspects alone appeal only to a minority of electricity consumers, marketing of demand response may be easier in areas where reliability has been an issue.

The expected payback times for investing in demand response enabling technologies are relatively short regardless of respondents' expertise. This may be because longer payback times can be considered more risky because recovering the investment depends on the price level and structure of future electricity tariffs. On the other hand, consumers may feel that larger investments should be made by the industry as it has opportunity to larger savings than an individual customer.

\section{REFERENCES}

1. Federal Energy Regulatory Commission, Assessment of demand response \& advanced metering, December

2012 , http://www.ferc.gov/legal/staff-reports/12-20-12-demand-response.pdf [Accessed: 15-Jan-2013]

2. U.S. Department of Energy, Benefits of demand response in electricity markets and recommendations for achieving them - A Report to the United States Congress pursuant to Section 1252 of the Energy Policy Act of 2005, http://energy.gov/sites/prod/files/oeprod/DocumentsandMedia/DOE_Benefits_of_Dem and_Response_in_Electricity_Markets_and_Recommendations_for_Achieving_Them_ Report_to_Congress.pdf, [Accessed: 15-Jan-2014]

3. Kim, J.-H. and Shcherbakova, A., Common failures of demand response, Energy, Vol. 36, No. 2, pp. 873-880, 2011, http://dx.doi.org/10.1016/j.energy.2010.12.027

4. Gyamfi, S., Krumdieck, S., and Urmee, T., Residential peak electricity demand response - Highlights of some behavioural issues, Renewable and Sustainable Energy Reviews, Vol. 25, pp. 71-77, 2013, http://dx.doi.org/10.1016/j.rser.2013.04.006

5. Ontario Energy Board, Ontario Energy Board smart price pilot - Final report, July 2007, http://www.ontarioenergyboard.ca/documents/cases/EB-2004-0205/smartpricepilot/OS PP\%20Final\%20Report\%20-\%20Final070726.pdf, [Accessed 24-Jan-2014]

6. City of Roseville, Power 2013. http://www.roseville.ca.us/electric/home/power_partners/default.asp, [Accessed: 15-May-2013]

7. City of Columbia, Load management, 2013. http://www.gocolumbiamo.com/WaterandLight/Conservation/load.php, [Accessed: 15-May-2013] 
8. Ariu, T., Lewis, P.E., Goto, H., Dromacque, C., and Brennan, S., Impacts and lessons from the fully liberalized European electricity market - Residential customer price, switching and services. CRIEPI Report: Y11018, 2012.

9. Faruqui, A. and George, S., Quantifying customer response to dynamic pricing, Electricity Journal, Vol. 18, No. 4, pp. 53-63, 2005, http://dx.doi.org/10.1016/j.tej.2005.04.005

10.Wolak, F., Residential customer response to real-time pricing: The Anaheim critical-peak pricing experiment, CSEM WP 151, 2006. http://escholarship.org/uc/item/3td3n1x1, [Accessed: 29-Jan-2014]

11.Faruqui, A. and Sergici, S., Household response to dynamic pricing of electricity: a survey of 15 experiments, Journal of Regulatory Economics, Vol. 38, No. 2, pp. 193-225, 2010, http://dx.doi.org/10.1007/s11149-010-9127-y

12.Borenstein, S., The long-run efficiency of real-time electricity pricing, Energy Journal, Vol. 26, No. 3, pp. 93-116, 2005, http://dx.doi.org/10.5547/ISSN0195-6574-EJ-Vol26-No3-5

13.Allcott, H., Rethinking real-time electricity pricing, Resource and Energy Economics, Vol. 33, No. 4, pp. 820-842, 2011, http://dx.doi.org/10.1016/j.reseneeco.2011.06.003

14.Dütschke, E. and Paetz, A.-G., Dynamic electricity pricing - Which programs do consumers prefer?, Energy Policy, Vol. 59, pp. 226-234, 2013, http://dx.doi.org/10.1016/j.enpol.2013.03.025

15.Hydro One Networks Inc., Time-of-use pricing pilot project results, EB-2007-0086, http://www.oeb.gov.on.ca/documents/cases/EB-2004-0205/smartpricepilot/TOU_Pilot _Report_HydroOne_20080513.pdf, [Accessed 24-Jan-2014]

16.Ericson, T., Households' self-selection of dynamic electricity tariffs, Applied Energy, Vol. 88, No. 7, pp. 2541-2547, 2011, http://dx.doi.org/10.1016/j.apenergy.2011.01.024

17.Paetz, A.-G., Dütschke, E., and Fichtner, W., Smart homes as a means to sustainable energy consumption: A study of consumer perceptions, Journal of Consumer Policy, Vol. 35, No. 1, pp. 23-41, 2012, http://dx.doi.org/10.1007/s10603-011-9177-2

18.Lutzenhiser, S., Peters, J., Moezzi, M., and Woods, J., Beyond the price effect in time-of-use programs: Results from a municipal utility pilot, 2007-2008. Lawrence Berkeley National Laboratory, 2009. http://www.escholarship.org/uc/item/3673h6r7\#, [Accessed: 29-Jan-2014]

19.Fritz, P., Jörgensen, E. and Lindskoug, S., Att följa elpriset batter. Prismodeller och $\begin{array}{lllll}\text { styrteknik } \quad \mathrm{i} \text { fältförsök, } & \text { 09:70, }\end{array}$ http://www.elforsk.se/Rapporter/?rid=09_70_, [Accessed: 29-January-2014]

20.Commission for Energy Regulation, Electricity smart metering customer behaviour trials (CBT) findings report. Information paper. CER11080a, 2011, http://www.cer.ie/docs/000340/cer11080\%28a\%29\%28i\%29.pdf, [Accessed: 29-Jan-2014]

21.Thorsnes, P., Williams, J., and Lawson, R., Consumer responses to time varying prices for electricity, Energy Policy, Vol. 49, pp. 552-561, 2012, http://dx.doi.org/10.1016/j.enpol.2012.06.062

22.Horst, G., Consumer engagement: Facts, myths \& motivations, Proceedings of Grid-Interop Forum 2011, Phoenix, December 5-8, 2011.

23.McKenna, E., Richardson, I., and Thomson, M., Smart meter data: Balancing consumer privacy concerns with legitimate applications, Energy Policy, Vol. 41, pp. 807-814, 2012, http://dx.doi.org/10.1016/j.enpol.2011.11.049

24.Annala, S., Viljainen, S., and Tuunanen, J., Demand response from residential customers' perspective, Proceedings of EEM12 $9^{\text {th }}$ International Conference on the European Energy Market, Florence, May 10-12, 2012. 
25.Annala, S., Viljainen, S., and Tuunanen, J., Rationality of supplier switching in retail electricity markets, International Journal of Energy Sector Management, Vol. 7, No. 4, pp. 459-477.

26.Alexander, B.R., Dynamic pricing? Not so fast! A residential consumer perspective, Electricity Journal, Vol. 23, No. 6, pp. 39-49, 2010, http://dx.doi.org/10.1016/j.tej.2010.05.014

27.Gyamfi, S. and Krumdieck, S., Price, environment and security: Exploring multi-modal motivation in voluntary residential peak demand response, Energy Policy, Vol. 39, No. 5, pp. 2993-3004, http://dx.doi.org/10.1016/j.enpol.2011.03.012 